\title{
Estrogen-Related Receptor $\alpha$, the Molecular Clock, and Transcriptional Control of Metabolic Outputs
}

\author{
V. Giguk̀re ${ }^{1,2}$, C.R. Dufour ${ }^{1}$, L.J. Eichner ${ }^{1,2}$, G. Deblois ${ }^{1,2}$, And N. Cermakian ${ }^{3}$ \\ ${ }^{1}$ Goodman Cancer Research Centre, McGill University, Montréal, Québec, Canada H3A 1A3 \\ ${ }^{2}$ Department of Biochemistry, McGill University, Montréal, Québec, Canada H3G 1Y5 \\ ${ }^{3}$ Laboratory of Molecular Chronobiology, Douglas Mental Health University Institute, \\ Montréal, Québec, Canada H4H 1R3 \\ Correspondence: vincent.giguere@mcgill.ca
}

\begin{abstract}
Metabolism and circadian rhythms must be closely integrated to support the energetic needs of the organism linked to the daily timing of physiological and behavioral processes. Although components of the molecular clock can directly target some metabolic genes, the control of metabolic clock output is believed to be mediated mostly through the action of transcription factors whose patterns of expression are rhythmic in metabolic tissues. Our recent work has identified the orphan nuclear receptor estrogen-related receptor $\alpha(E R R \alpha)$, a potent effector of metabolic gene networks, as a direct regulator of the molecular clock. Thus, by acting both upstream of and downstream from the molecular clock, ERR $\alpha$ serves as a key transcription factor linking the clock with metabolic control.
\end{abstract}

Circadian rhythms and metabolic control are closely linked physiological processes. Indeed, genome-wide transcriptome analyses have shown that a significant number of genes display patterns of expression that are rhythmic in metabolic tissues. These genes predominantly encode enzymes involved in glucose homeostasis, fatty acid oxidation, cholesterol synthesis, and degradation as well as transcription factors that operate as output regulators of the circadian clock. In particular, 20 members of the superfamily of nuclear receptors have been shown to be expressed in a rhythmic fashion in metabolically active tissues such as the liver, skeletal muscle, and white and brown fat (Yang et al. 2006). Nuclear receptors are especially well suited to act as output regulators of the clock as they can translate hormonal, metabolites, and nutrient signals into specific expression signatures of metabolic genes (Yang 2010). Herein, we present evidence that identifies the orphan nuclear receptor estrogen-related receptor $\alpha(\mathrm{ERR} \alpha, \mathrm{NR} 3 \mathrm{~B} 1)$ and its corepressor PROX1 as novel transcriptional regulators of the molecular clock. We further demonstrate that the clock factor BMAL1 regulates a larger number of metabolic genes than previously anticipated and that many of these targets are shared with ERR $\alpha$ and PROX1. When combined with its known role in the control of energy homeostasis, our work demonstrates that ERR $\alpha$ serves as a key transcription factor connecting peripheral clock function and cellular energy metabolism.

\section{ERR $\alpha$ : A COMPREHENSIVE REGULATOR OF MITOCHONDRIAL BIOGENESIS AND ENERGY METABOLISM}

ERR $\alpha$ was the first member of the superfamily of nuclear receptors to be labeled as an orphan receptor (Giguère et al. 1988). Despite its close structural similarity to the estrogen receptor, ERR $\alpha$ does not bind natural estrogens, recognize the same regulatory sequences as the estrogen receptor in genomes, nor regulate reproductive or other known estrogenic-related functions (Sladek et al. 1997; Lu et al. 2001; Luo et al. 2003; Deblois et al. 2009). Instead, $\mathrm{ERR} \alpha$ plays a critical role in the control of energy metabolism and mitochondrial biogenesis (Giguère 2008; Villena and Kralli 2008; Deblois and Giguère 2011; Eichner and Giguère 2011). First, ERR $\alpha$ displays high expression levels in tissues with elevated metabolic demands such as the heart, kidney, skeletal muscle, intestine, and brown adipose tissue. Second, the transcriptional activity of $\mathrm{ERR} \alpha$ is highly dependent on the presence of peroxisome proliferator-activated receptor $\gamma(\operatorname{PPAR} \gamma)$-coactivator $1 \alpha$ (PGC-1 $\alpha$ ) and PGC-1 $\beta$, two transcriptional coactivator proteins known to be essential regulators of energy metabolism (Lin et al.2005). Equally, the transcriptional activity of the ERR $\alpha-\mathrm{PGC}-1 \alpha$ complex is inhibited by prosperorelated homeobox 1 (PROX1) (Charest-Marcotte et al. 2010). PROX1 and $E R R \alpha$ share as genomic targets the promoter region of numerous metabolic genes involved in carbohydrate and fatty acid metabolism, tricarboxylic acid (TCA) cycle, and oxidative phosphorylation. In addition, the PROX1 locus has recently been linked to fasting glucose homeostasis in human subjects (Dupuis et al. 2010). Third, overexpression of PGC- $1 \alpha$ or ERR $\alpha$ itself demonstrated a direct link between these transcription factors and changes in the expression of vast networks of metabolic genes (Huss et al. 2004; Mootha et al. 2004; Schreiber et al. 2004; Gaillard et al. 2006). Fourth, genome-wide location analyses by chromatin immunoprecipitation (ChIP) showed enrichment of ERR $\alpha$ at regulatory regions of a large number of metabolic genes 
(Dufour et al. 2007; Sonoda et al. 2007; Chen et al. 2008; Deblois et al. 2009; Charest-Marcotte et al. 2010; Tremblay et al. 2010). In fact, ERR $\alpha$ occupies the promoter regions of practically all genes encoding enzymes involved in glycolysis, pyruvate metabolism, and the TCA cycle (Charest-Marcotte et al. 2010) as well as the vast majority of genes encoding mitochondrial proteins (Eichner and Giguère 2011). Fifth, ablation of the ERR $\alpha$ gene in mice has been shown to disrupt mitochondrial function in the heart (Huss et al. 2007), macrophages (Sonoda et al. 2007), and brown adipose (Villena et al. 2007), resulting in profound tissue-specific physiological dysfunctions.

\section{CIRCADIAN EXPRESSION OF ERR $\alpha$ AND PROX1}

$\mathrm{ERR} \alpha$ transcripts display a diurnal rhythm in several tissues, including liver, kidney, uterus, and bone (Horard et al. 2004; Yang et al. 2006; Tremblay et al. 2010; Dufour et al. 2011). In the liver of ad libitum fed mice, Esrra is expressed rhythmically (Dufour et al. 2011). The lowest level of Esrra expression was observed at Zeitgeber time (ZT) 4 with peak levels at ZT 12 and ZT 20. Esrra expression is under the control of the circadian clock, as it was shown that the hepatic rhythmic expression of Esrra under constant darkness in Clock mutant mice is lost (Horard et al. 2004). Nuclear ERR $\alpha$ protein levels were found to increase during the dark cycle of the day and, intriguingly, were found to be expressed antiphase to that of BMAL1 (Dufour et al. 2011). Proxl expression is also cyclic with two expression peaks at CT 10 and CT 18 that are abolished in Clock-mutant mice under dark/ dark conditions (Dufour et al. 2011). Unlike in constant darkness, Prox 1 oscillates with one expression peak during the night in light-entrained conditions, suggesting that Prox 1 expression is influenced by light. These data indicate that Prox 1 expression is rhythmic and under the direct control of the molecular clock.

\section{DISRUPTION OF CIRCADIAN PHYSIOLOGY IN ERR $\alpha$ KNOCKOUT MICE}

Mice lacking ERR $\alpha$ have been shown to display impaired diurnal blood pressure levels that are associated with alterations in the expression of $\mathrm{Na}^{+}$and $\mathrm{K}^{+}$transporters in the kidneys (Tremblay et al. 2010). ERR $\alpha$-null mice have also significantly lower glucose levels at ZT 12 and ZT 0/24, coinciding with the start and end of the dark cycle, respectively (Dufour et al. 2011). Food availability is a determinant in the observed differences in circulating glucose levels in ERR $\alpha$-null mice because the time-dependent hypoglycemia is lost under fasting conditions (Dufour et al. 2011). Furthermore, glucose tolerance tests performed at ZT 12 showed that basal glucose measurements were significantly lower in ERR $\alpha$-null mice, but no difference in glucose levels was seen postglucose injection. In contrast, glucose tolerance tests at ZT 0/24 revealed that $E R R \alpha$-null mice have improved glucose handling, demonstrated by significantly decreased basal blood glucose levels after a 6-h fast and at each subsequent time-point postglucose administration (Dufour et al. 2011). Indeed, fed ERR $\alpha$-null mice have significantly lower insulin levels at ZT 16 (Dufour et al. 2011). The delay in insulin secretion during the dark cycle observed in ERR $\alpha$-null mice reflects the trend toward latency in glucose uptake seen under fed ad libitum conditions. $\mathrm{ERR} \alpha$ expression is also important in maintaining the diurnal levels of circulating metabolites. ERR $\alpha$-null mice have significantly greater serum bile acids at ZT $0 / 24$ and ZT 4 under fed and fasted conditions, respectively (Dufour et al. 2011). Conversely, ERR $\alpha$-null mice have less circulating cholesterol, nonesterified fatty acids, and triglycerides, as determined throughout a complete 12-h light or dark cycle. ERR $\alpha$-null mice also display significantly lower activity levels, run significantly less in the hours preceding lights-off (ZT 10-12), and present an earlier activity offset (Dufour et al. 2011). The ERR $\alpha$-null mice also exhibit a free-running period significantly shorter than that of wild-type mice. In addition, mice lacking ERR $\alpha$ displayed lower activity levels during a 24-h period and a lower proportion of their activity in the subjective day under dark/dark conditions. Overall, these results indicate that $\operatorname{ERR} \alpha$ plays a key role in clock-related output pathways linked to metabolic homeostasis.

\section{ERR $\alpha$ IS A DIRECT REGULATOR OF THE CIRCADIAN CLOCK}

A recent genome-wide ChIP-on-chip analysis of ERR $\alpha$ binding to locations in the mouse liver has provided direct evidence for the regulation of the molecular clock by ERR $\alpha$ (Charest-Marcotte et al. 2010). Indeed, ERR $\alpha$ binds in the promoter region of the core clock genes Arntl (known as Bmal1), Clock, Cry1, Per2, Nr1d1 (known as Rev-erb $\alpha$ ), Nrld2 (known as Rev-erb $\beta$ ), Csnkld, and Bhlhe40 (known as Decl). ERR $\alpha$-binding elements (ERREs) were also found at ERR $\alpha$-binding sites, strongly suggesting a direct interaction of ERR $\alpha$ with genomic DNA at these loci. Furthermore, mice lacking $\operatorname{ERR} \alpha$ have altered diurnal rhythms of the clock genes Bmall, Clock, Cryl, and Rev-erb $\alpha$ (Dufour et al. 2011). In all cases, a difference in expression amplitude rather than a phase shift was observed in ERR $\alpha$-null livers compared with wild type. The livers of ERR $\alpha$-null mice express higher levels of Bmall between ZT 16 and ZT 24, less Clock and Rev-erb $\alpha$ levels at ZT 8, and more Cryl levels at ZT 20. As expected from the mRNA profiling data, BMAL1 protein levels are greatly increased across the day in mouse liver lacking ERR $\alpha$. This result demonstrates that normal ERR $\alpha$ activity results in strong repression of BMAL1. In contrast, CLOCK protein levels were found to be relatively constant throughout the day in both wild-type and ERR $\alpha$-null livers (Dufour et al. 2011). These data thus provide evidence for $\operatorname{ERR} \alpha$ as a direct transcriptional regulator of clock gene expression in mouse liver under ad libitum feeding. 


\section{ERR $\alpha$ REGULATES THE DIURNAL EXPRESSION OF METABOLIC GENES AND THEIR REGULATORS}

The importance of ERR $\alpha$ expression in regulating the diurnal expression of genes involved in metabolism under fed conditions was also investigated by our laboratory (Dufour et al. 2011). The hepatic diurnal expression of transcriptional regulators known to play a role in metabolic control, such as Dbp, Esrrg (encoding ERR $\gamma$, NR3B3), Ppargcla (encoding PGC-1 $\alpha$ ), and $\mathrm{NrOb2}$ (encoding the nuclear receptor SHP), was found to be significantly altered in ERR $\alpha$-null mice. Furthermore, microRNA $m i R-378^{*}$, recently shown to act as a negative regulator of the TCA cycle and oxidative metabolism by downregulating ERR $\gamma$ and GABPA expression (Eichner et al. 2010), was also found to have an altered diurnal expression in ERR $\alpha$-null mice. In ERR $\alpha$-null liver, altered messenger RNA (mRNA) oscillations of the metabolic genes Pckl, Pdhal, Pdk4, G6pc, and Gck, involved in glycolysis/gluconeogenesis, was observed (Dufour et al. 2011). The expression of the gluconeogenic genes Pckl and G6pc was shown to be significantly up-regulated in ERR $\alpha$-null liver at ZT 4 during the fasting phase of the light/dark (LD) cycle, where ERR $\alpha$ expression is normally at its lowest. At this time point, the transcript encoding PGC- $1 \alpha$, a known activator of the gluconeogenic transcriptional program, is also drastically increased in the absence of ERR $\alpha$. These data are in agreement with the previous report demonstrating that ERR $\alpha$ acts as a repressor of gluconeogenesis (Herzog et al. 2006). ERR $\alpha$-null livers also express altered diurnal rhythms of the genes Gys2, Pik3r1, Gys1, Lipe, Stk11 (encoding LKB1), Acacb (encoding ACC2), and Mlycd. The diurnal expression patterns of genes involved in fatty acid, cholesterol, and bile acid metabolism also depend on ERR $\alpha$. More specifically, Acadm, encoding the enzyme MCAD, important in fatty acid $\beta$-oxidation (Sladek et al. 1997), and Hmgcr, encoding the ratelimiting enzyme HMG-CoA reductase in cholesterol biosynthesis (Goldstein and Brown 1990), are up-regulated in $E R R \alpha$-null mice at specific times during the day. In addition, hepatic genes involved in bile acid biosynthesis and transport, Cyp7a1, Cyp8b1, and Abcb11 (encoding BSEP), are generally down-regulated in the absence of ERR $\alpha$. The expression profiles of genes associated with mitochondrial energy production were also explored in this study (Dufour et al. 2011). Overall, a significant reduction in the expression profiles across a 24-h cycle of many TCA cycle and oxidative phosphorylation genes, including Cs, Aco2, Sdhd, Cycs, and Ndufb5, was found in ERR $\alpha$-null liver. Taken together, these data define ERR $\alpha$ as an important player in the diurnal regulation of clock gene expression and of many metabolic genes involved in clock-controlled physiological outputs.

\section{GENOMIC CONVERGENCE AMONG ERR $\alpha$, PROX1, AND BMAL1 IN CLOCK METABOLIC OUTPUTS}

Our laboratory next sought to determine the extent of the functional relationship among BMAL1, ERR $\alpha$, and PROX1 in the direct control of metabolic gene networks. ChIP-on-chip experiments were performed using antibodies against all three factors and chromatin obtained from mouse liver taken at ZT 4 in LD conditions (CharestMarcotte et al. 2010; Dufour et al. 2011). These datasets first showed that BMAL1 binds a significant number of promoters of genes involved in a broad range of metabolic processes, including amino acid, lipid, carbohydrate, and TCA cycle/oxidative phosphorylation. In addition, $\sim 15 \%$ of the BMAL1 target genes encode transcription factors, including numerous nuclear receptors involved in metabolic control. BMAL1 also binds to the promoter regions of core clock genes, including Cry2, Dbp, Dec1, Dec2, Per1, Per2, Per 3, and Rev-erb $\alpha$. Furthermore, these experiments revealed previously unidentified binding sites for BMAL1/CLOCK within the promoters of Bmall and Clock themselves as well as in the Csnkld promoter (Dufour et al. 2011). These data not only show that BMAL1/CLOCK can directly bind to the core clock genes but also that they can directly bind to their own promoters, thus identifying a previously unrecognized autoregulatory loop. Comparison between ERR $\alpha$ and BMAL1 targets shows that $\sim 37 \%$ of genes are shared by both factors. A significant number of common targets (e.g., Pckl, Hmgcr, NrOb2) were found to have altered cyclic expression patterns in ERR $\alpha$-null mice. As expected, ERR $\alpha$-specific targets are enriched in metabolic and energy-producing processes including inositol metabolism, lipid metabolism, the TCA cycle, ubiquinone biosynthesis, and oxidative phosphorylation. Similarly, targets shared by ERR $\alpha$ and BMAL1 are also associated with metabolic processes such as AMP kinase and insulin receptor signaling in addition to glycolysis and gluconeogenesis. BMAL1 was also found to be enriched at more than 300 target genes associated with transcriptional regulation, including genes encoding 14 nuclear receptors as well as the transcription factors ATF2-7, DBP, HIF $1 \alpha$, IRF8, GABPA, and STAT3 and the transcriptional coregulators PGC- $1 \alpha$, PGC- $1 \beta$, NCoR1, and PROX1. In particular, these data uncovered that ERR $\alpha$ and PROX1 are direct downstream targets of BMAL1/CLOCK. Similarly, ChIP-on-chip experiments showed PROX1 recruitment to the clock target genes Bmal1, Clock, Cryl, Cry2, Csnk1d, Decl, Per1, Rev-erb $\alpha$, and Rev-erb $\beta$. In agreement with the ChIP-chip experiments, ablation of PROX1 in HepG2 cells results in an increase in Bmal1, Clock, Cry2, and Decl expression as well as a decrease in Csnkld, Rev-erb $\alpha$, and Rev-erb $\beta$ levels (Dufour et al. 2011). Furthermore, ablation of PROX1 in synchronized HepG2 cells resulted in significantly altered oscillations and abundances of clock gene transcripts. These data show that PROX1 is a regulator of the molecular clock by acting as either an activator or repressor of clock gene expression. Moreover, altered expression rhythms of Pck1, Slc2a2, and Aldoc involved in glucose homeostasis in the absence of PROX1 were observed in synchronized HepG2 cells. As observed for ERR $\alpha$, PROX1 can thus function as both an upstream clock regulator and a direct downstream mediator of clock function. Further analyses of the gene networks commonly regulated 


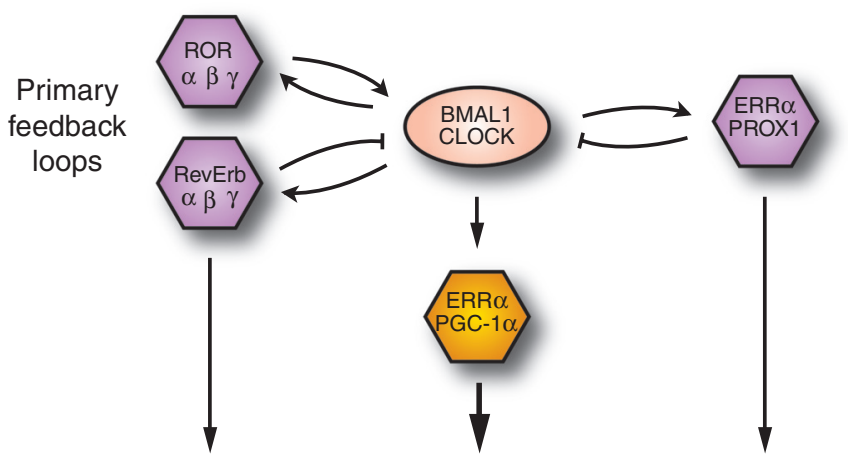

Output regulators and metabolic genes $\downarrow$

Output metabolic processes
Figure 1. A model for the role of ERR $\alpha$ in circadian biology. The ERR $\alpha-P R O X 1$ complex may act, in a manner analogous to that of the RevErb and ROR isoforms, as a primary feedback loop regulating the expression of the molecular clock. Current data suggest that $E R R \alpha$ probably functions by contributing to the robustness of the rhythmic expression of BMAL1 and its target genes. BMAL1 targets include a vast network of metabolic genes, a network that is shared with ERR $\alpha$ and its coregulators PGC- $1 \alpha$ and PROX1, suggesting a basic interdependence between BMAL1 and ERR $\alpha$ in the control of the daily timing of metabolic processes. by $\mathrm{ERR} \alpha$, PROX 1 , and/or BMAL 1 show that $\sim 36 \%$ of all BMAL1 target genes are common to PROX1 and BMAL1 and that $\sim 35 \%$ of all BMAL1 target genes are shared by ERR $\alpha$ and BMAL1 (Dufour et al. 2011). Overall, more than 500 targets are shared by all three factors $(\sim 20 \%$ of all three datasets), revealing a significant level of coordination in the control of these gene networks. In addition, comparative analysis of these datasets with mouse liver circadian expression data compiled from experiments performed with mice under basal conditions maintained in constant darkness (Akhtar et al. 2002; Panda et al. 2002; Storch et al. 2002; Ueda et al. 2002; Hughes et al. 2009) indicates that a large subset of $E R R \alpha$, BMAL1, and PROX1 target genes displays rhythmic expression in the liver. Of interest, genes commonly targeted by either BMAL1 and $\mathrm{ERR} \alpha, \mathrm{BMAL1}$, and PROX1 or by all three factors are enriched for metabolic genes (e.g., fatty acid and carbohydrate metabolism) as compared with genes targeted by BMAL1 alone.

\section{CONCLUSION: A KEY ROLE FOR ERR $\alpha$ IN CIRCADIAN BIOLOGY}

Given the strong inhibitory action of ERR $\alpha$ on BMAL1 expression in the liver, the orphan nuclear receptor ERR $\alpha$ can find its place alongside the six RevErb and ROR isoforms (Guillaumond et al. 2005), themselves nuclear receptors, as components of primary feedback loops regulating the rhythmic expression of BMAL1 and transcriptional activity of BMAL1/CLOCK (Fig. 1). Moreover, $\mathrm{ERR} \alpha$ can now be included in this rare class of transcription factors, mostly nuclear receptors, that concomitantly regulate the expression of the components of the molecular clock and its output metabolic pathways. ERR $\alpha$ accomplishes this task through interactions with both positive and negative coregulatory proteins, such as PGC- $1 \alpha$ and PROX1, themselves rhythmically expressed in the liver. In conclusion, genomic convergence of $\operatorname{ERR} \alpha$,
PROX1, and BMAL1 transcriptional activity as assessed by genome-wide location analyses and gene expression profiling together with phenotypic analyses of the ERR $\alpha$ null mouse identified ERR $\alpha$ as a novel and key component of the molecular circuitry regulating the circadian rhythms of metabolic processes.

\section{ACKNOWLEDGMENTS}

This work was supported by grants from the Canadian Institutes for Health Research (MOP-84227 and MOP111144 ) to V.G. and a grant from the National Sciences and Engineering Research Council to N.C.

\section{REFERENCES}

Akhtar RA, Reddy AB, Maywood ES, Clayton JD, King VM, Smith AG, Gant TW, Hastings MH, Kyriacou CP. 2002. Circadian cycling of the mouse liver transcriptome, as revealed by cDNA microarray, is driven by the suprachiasmatic nucleus. Curr Biol 12: 540-550.

Charest-Marcotte A, Dufour CR, Wilson BJ, Tremblay AM, Eichner LJ, Arlow DH, Mootha VK, Giguère V. 2010. The homeobox protein Prox1 is a negative modulator of ERR $\alpha$ / PGC-1 $\alpha$ bioenergetic functions. Genes Dev 24: 537-542.

Chen X, Xu H, Yuan P, Fang F, Huss M, Vega VB, Wong E, Orlov YL, Zhang W, Jiang J, et al. 2008. Integration of external signaling pathways with the core transcriptional network in embryonic stem cells. Cell 133: 1106-1117.

Deblois G, Giguère V. 2011. Functional and physiological genomics of estrogen-related receptors (ERRs) in health and disease. Biochim Biophys Acta 1812: 1032-1040.

Deblois G, Hall JA, Perry MC, Laganiere J, Ghahremani M, Park M, Hallett M, Giguère V. 2009. Genome-wide identification of direct target genes implicates estrogen-related receptor $\alpha$ as a determinant of breast cancer heterogeneity. Cancer Res 69: 6149-6157.

Dufour CR, Wilson BJ, Huss JM, Kelly DP, Alaynick WA, Downes M, Evans RM, Blanchette M, Giguère V. 2007. Genome-wide orchestration of cardiac functions by orphan nuclear receptors ERR $\alpha$ and $\gamma$. Cell Metab 5: 345-356.

Dufour CR, Levasseur M-P, Pham NHH, Eichner LJ, Wilson BJ, Charest-Marcotte A, Duguay D, Poirier-Héon J-F, Cermakian 
N, Giguère V. 2011. Genomic convergence among ERR $\alpha$, Prox1, and Bmal1 in the control of metabolic clock outputs. PLoS Genet 7: e1002143.

Dupuis J, Langenberg C, Prokopenko I, Saxena R, Soranzo N, Jackson AU, Wheeler E, Glazer NL, Bouatia-Naji N, Gloyn $\mathrm{AL}$, et al. 2010. New genetic loci implicated in fasting glucose homeostasis and their impact on type 2 diabetes risk. Nat Genet 42: 105-116.

Eichner LJ, Giguère V. 2011. Estrogen-related receptors (ERRs): A new dawn in the control of mitochondrial gene networks. Mitochondrion 11: 544-552.

Eichner LJ, Perry M-C, Dufour CR, Bertos N, Park M, St-Pierre J, Giguère V. 2010. mir-378* mediates metabolic shift in breast cancer cells via the PGC-1 $\beta /$ ERR $\gamma$ transcriptional pathway. Cell Metab 12: 352-361.

Gaillard S, Grasfeder LL, Haeffele CL, Lobenhofer EK, Chu TM, Wolfinger R, Kazmin D, Koves TR, Muoio DM, Chang CY, McDonnell DP. 2006. Receptor-selective coactivators as tools to define the biology of specific receptor-coactivator pairs. Mol Cell 24: 797-803.

Giguère V. 2008. Transcriptional control of energy homeostasis by the estrogen-related receptors. Endocr Rev 29: 677-696.

Giguère V, Yang N, Segui P, Evans RM. 1988. Identification of a new class of steroid hormone receptors. Nature 331: 91-94.

Goldstein JL, Brown MS. 1990. Regulation of the mevalonate pathway. Nature 343: 425-430.

Guillaumond F, Dardente H, Giguere V, Cermakian N. 2005. Differential control of Bmall circadian transcription by REVERB and ROR nuclear receptors. J Biol Rhythms 20: 391-403.

Herzog B, Cardenas J, Hall RK, Villena JA, Budge PJ, Giguère V, Granner DK, Kralli A. 2006. Estrogen-related receptor $\alpha$ is a repressor of phosphoenolpyruvate carboxykinase gene transcription. J Biol Chem 281: 99-106.

Horard B, Rayet B, Triqueneaux G, Laudet V, Delaunay F, Vanacker JM. 2004. Expression of the orphan nuclear receptor $\mathrm{ERR} \alpha$ is under circadian regulation in estrogen-responsive tissues. J Mol Endocrinol 33: 87-97.

Hughes ME, DiTacchio L, Hayes KR, Vollmers C, Pulivarthy S, Baggs JE, Panda S, Hogenesch JB. 2009. Harmonics of circadian gene transcription in mammals. PLoS Genet 5: e1000442.

Huss JM, Pineda Torra I, Staels B, Giguère V, Kelly DP. 2004 Estrogen-related receptor $\alpha$ directs peroxisome proliferatoractivated receptor $\alpha$ signaling in the transcriptional control of energy metabolism in cardiac and skeletal muscle. Mol Cell Biol 24: 9079-9091.

Huss JM, Imahashi K-I, Dufour C, Weinheimer CJ, Courtois M, Kovacs A, Giguère V, Murphy E, Kelly DP. 2007. The nuclear receptor ERR $\alpha$ is required for the bioenergetic and functional adaption to cardiac pressure overload. Cell Metab 6: 25-37.

Lin J, Handschin C, Spiegelman BM. 2005. Metabolic control through the PGC-1 family of transcription coactivators. Cell Metab 1: 361-370.
Lu D, Kiriyama Y, Lee KY, Giguère V. 2001. Transcriptional regulation of the estrogen-inducible $\mathrm{pS} 2$ breast cancer marker gene by the ERR family of orphan nuclear receptors. Cancer Res 61: 6755-6761.

Luo J, Sladek R, Carrier J, Bader J-A, Richard D, Giguère V. 2003. Reduced fat mass in mice lacking orphan nuclear receptor estrogen-related receptor $\alpha$. Mol Cell Biol 23: 7947-7956.

Mootha VK, Handschin C, Arlow D, Xie X, St Pierre J, Sihag S, Yang W, Altshuler D, Puigserver P, Patterson N, et al. 2004. ERR $\alpha$ and GABPA $\alpha / \beta$ specify PGC- $1 \alpha$-dependent oxidative phosphorylation gene expression that is altered in diabetic muscle. Proc Natl Acad Sci 101: 6570-6575.

Panda S, Antoch MP, Miller BH, Su AI, Schook AB, Straume M, Schultz PG, Kay SA, Takahashi JS, Hogenesch JB. 2002. Coordinated transcription of key pathways in the mouse by the circadian clock. Cell 109: 307-320.

Schreiber SN, Emter R, Hock MB, Knutti D, Cardenas J, Podvinec M, Oakeley EJ, Kralli A. 2004. The estrogen-related receptor alpha $(E R R \alpha)$ functions in PPAR $\gamma$ coactivator $1 \alpha$ (PGC-1 $\alpha$ )-induced mitochondrial biogenesis. Proc Natl Acad Sci 101: 6472-6477.

Sladek R, Bader J-A, Giguère V. 1997. The orphan nuclear receptor estrogen-related receptor $\alpha$ is a transcriptional regulator of the human medium-chain acyl coenzyme A dehydrogenase gene. Mol Cell Biol 17: 5400-5409.

Sonoda J, Laganière J, Mehl IR, Barish GD, Chong LW, Li X, Scheffler IE, Mock DC, Bataille AR, Robert F, et al. 2007. Nuclear receptor ERR $\alpha$ and coactivator PGC-1 $\beta$ are effectors of IFN- $\gamma$ induced host defense. Genes Dev 21: 1909-1920.

Storch KF, Lipan O, Leykin I, Viswanathan N, Davis FC, Wong WH, Weitz CJ. 2002. Extensive and divergent circadian gene expression in liver and heart. Nature 417: 78-83.

Tremblay AM, Dufour CR, Ghahremani M, Reudelhuber TL, Giguère V. 2010. Physiological genomics identifies estrogenrelated receptor $\alpha$ as a regulator of renal sodium and potassium homeostasis and the renin-angiotensin pathway. Mol Endocrinol 24: 22-32.

Ueda HR, Chen W, Adachi A, Wakamatsu H, Hayashi S, Takasugi T, Nagano M, Nakahama K, Suzuki Y, Sugano S, et al. 2002. A transcription factor response element for gene expression during circadian night. Nature 418: 534-539.

Villena JA, Kralli A. 2008. ERR $\alpha$ : A metabolic function for the oldest orphan. Trends Endocrinol Metab 19: 269-276.

Villena JA, Hock MB, Giguère V, Kralli A. 2007. Orphan nuclear receptor ERR $\alpha$ is essential for adaptive thermogenesis. Proc Natl Acad Sci 104: 1418-1423.

Yang X. 2010. A wheel of time: The circadian clock, nuclear receptors, and physiology. Genes Dev 24: 741-747.

Yang X, Downes M, Yu RT, Bookout AL, He W, Straume M, Mangelsdorf DJ, Evans RM. 2006. Nuclear receptor expression links the circadian clock to metabolism. Cell 126: $801-810$ 


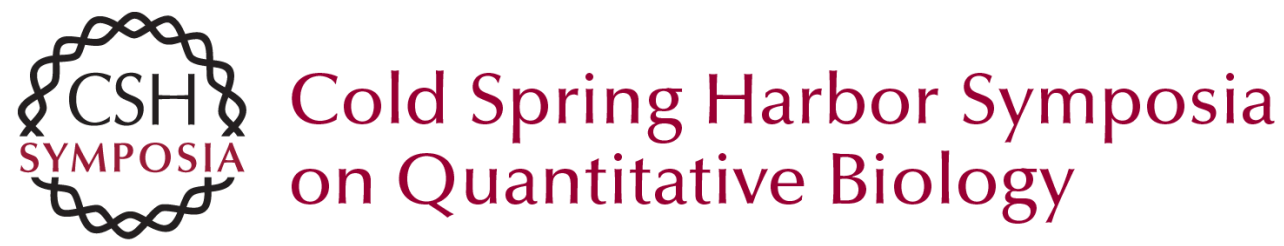

\section{Estrogen-Related Receptor $\alpha$, the Molecular Clock, and Transcriptional Control of Metabolic Outputs}

V. Giguère, C.R. Dufour, L.J. Eichner, et al.

Cold Spring Harb Symp Quant Biol 2011 76: 57-61 originally published online December 16, 2011

Access the most recent version at doi:10.1101/sqb.2011.76.011031

References This article cites 35 articles, 12 of which can be accessed free at: http://symposium.cshlp.org/content/76/57.full.html\#ref-list-1

\section{License}

Email Alerting Receive free email alerts when new articles cite this article - sign up in Service the box at the top right corner of the article or click here. 